Article

\title{
Effects of Different Ethanol/Diesel Blending Ratios on Combustion and Emission Characteristics of a Medium-Speed Diesel Engine
}

\author{
Zhiqiang Wang ${ }^{1,2}$ and Lijun $\mathrm{Li}^{1, *}$ \\ 1 School of Mechanical and Electrical Engineering, Central South University of Forestry and Technology, \\ Changsha 410004, China; zqwang@hnust.edu.cn \\ 2 College of Informational and Electrical Engineering, Hunan University of Science and Technology, \\ Xiangtan 411201, China \\ * Correspondence: T19930431@csuft.edu.cn
}

Citation: Wang, Z.; Li, L. Effects of Different Ethanol/Diesel Blending

Ratios on Combustion and Emission Characteristics of a Medium-Speed Diesel Engine. Processes 2022, 10, 173. https://doi.org/10.3390/pr10010173

Academic Editor: Albert Ratner

Received: 15 December 2021

Accepted: 12 January 2022

Published: 17 January 2022

Publisher's Note: MDPI stays neutral with regard to jurisdictional claims in published maps and institutional affiliations.

Copyright: (C) 2022 by the authors. Licensee MDPI, Basel, Switzerland. This article is an open access article distributed under the terms and conditions of the Creative Commons Attribution (CC BY) license (https:// creativecommons.org/licenses/by/ $4.0 /)$.

\begin{abstract}
In order to better evaluate the effects of ethanol/diesel blends on engine combustion and emission characteristics, we developed an engine cylinder model using the software CONVERGE combined with the program CHEMKIN. The model was validated experimentally. A modified chemical kinetic mechanism was used to calculate the combustion process of diesel fuel and ethanol for the diesel engine, including 154 reactions and 68 species. Furthermore, the influence of different ethanol proportions on diesel engine combustion and emission characteristics, including power, brake specific fuel consumption, brake thermal efficiency, cylinder pressure, cylinder temperature, nitrogen oxide $\left(\mathrm{NO}_{\mathrm{x}}\right)$, carbon monoxide $(\mathrm{CO})$, and soot emissions, was also investigated. Our results showed that cylinder pressure and temperature increased with increased ethanol content. When the ethanol content increased to $20 \%$ at $100 \%$ load, the cylinder pressure increased by $0.46 \%$, and the thermal efficiency increased by $3.63 \%$. However, due to the lower calorific value of ethanol, the power decreased by $4.12 \%$, and the brake specific fuel consumption increased by $4.23 \%$. In addition, the ethanol/diesel blends significantly reduced $\mathrm{CO}$ and soot emissions. Compared with diesel, soot and CO emissions from the D80E20 at 100\% load reduced by $63.25 \%$ and $17.24 \%$, respectively. However, $\mathrm{NO}_{\mathrm{x}}$ emission increased by $1.39 \%$.
\end{abstract}

Keywords: diesel engine; ethanol/diesel blended fuel; CONVERGE; combustion and emission characteristics

\section{Introduction}

Diesel engines are extensively used in both agriculture and industry due to their high thermal efficiency [1], good fuel efficiency [2], and higher power [3]. Although the diesel engine has brought prosperity to the world economy, it also faces more serious problems such as energy shortages and environmental pollution [4]; this has been a major scientific research topic for diesel engine researchers seeking ways to save energy and reduce emissions [5]. In order to reduce human dependence on fossil energy and adapt to increasingly stringent emission regulations, research on the application of renewable and clean fuels in energy consumption continues to receive extensive attention [6]. Biomass fuels represented by ethanol show great potential in reducing diesel consumption and exhaust gas emission. Some even completely replace fossil fuels and are applied to diesel engines $[7,8]$.

Ethanol has a certain calorific value and sufficient combustion; it can also be used as a clean oxygenated fuel [9]. Since it is inexpensive and easy to obtain, ethanol is suitable as an additional fuel blended with diesel [10]. The combustion flame propagation speed of ethanol is fast [11], the combustion efficiency is high, the combustion quality is good [12], and the incomplete combustion products $\mathrm{CO}$ and hydrocarbon (HC) are fewer [13]. Compared with diesel, ethanol has a higher latent heat of vaporization. Vaporization can reduce 
the maximum combustion temperature in the cylinder and reduce $\mathrm{NO}_{\mathrm{x}}$ emission [14]. Simultaneously, the pressure in the cylinder reduces, the air intake and charge coefficient increase, and the diesel power performance improves [15].

As an alternative fuel to petroleum, ethanol is a hot spot in contemporary research. Many studies show that [16-21] oxygenated fuel has many advantages over traditional fuel in optimizing emissions. Ethanol is a typical oxygenated fuel [22]. Ethanol preparation uses cellulose and other wastes as raw materials that belong to renewable energy. Biofuel ethanol decreases harmful emissions such as carbon dioxide $\left(\mathrm{CO}_{2}\right)$ and particles matter (PM), $\mathrm{CO}$, and $\mathrm{HC}$ in motor vehicle exhaust [23], which is conducive to improving the ecological environment [24]. As an oxygenated renewable fuel, ethanol has been widely studied and is suitable for improving diesel engine emissions and replacing fossil fuels [25]. Dongle et al. [26] studied the impact of fuel stratification on the combustion characteristics of diesel/ethanol dual-fuel engines. Their results showed that ethanol prolonged the ignition delay period. Pedrozo et al. [27] studied the impact of diesel/ethanol dual fuel on engine combustion characteristics and emissions. According to their results, the net indicated that the thermal efficiency of the dual-fuel engine was higher than the traditional diesel engine, with an average effective pressure range between 0.6 and 2.4 MPa. In addition, the use of the Miller cycle further improved net efficiency and reduced $\mathrm{NO}_{\mathrm{x}}$ emissions from diesel/ethanol dual-fuel engines.

In summary, the blending of ethanol and diesel can improve the combustion and emission characteristics of the engine significantly. In addition, with the development of computers, numerical engine simulation has become an important means of engine research and development [28,29]. Currently, widely used simulation software include ANSYS Fluent, CONVERGE, AVL-Fire, AVL-BOOST, etc. Fan et al. [30] studied the mixing formation and combustion of direct hydrogen injection and natural gas rotary injection engines using the software ANSYS FLUENT. Their results showed that with the increase in injection time, the hydrogen stratification became more apparent. Zhang et al. [31] used the software CONVERGE to study the influence of different fuel blending ratios on diesel engine spray, combustion, and emission characteristics. Gong et al. [32] simulated the effects of injection and ignition timing on engine combustion, in-cylinder formaldehyde, and unburned methanol emissions during the cold start of a methanol engine using AVLFire. Poorghasemi et al. [33] studied the effects of diesel injection strategy on NG/diesel RCCI combustion and emission characteristics using CONVERGE. Their results showed that changing the injection strategy reduces $\mathrm{NO}_{\mathrm{x}}$ emissions. However, there are few studies on the effects of low ethanol concentrations in diesel on fuel concentrations using mediumspeed diesel engines combined with detailed chemical kinetic mechanisms $[34,35]$.

In summary, we used the 3D computational fluid dynamics (CFD) software CONVERGE combined with the CHEMKIN program to numerically simulate the in-cylinder combustion process of a diesel engine. Our experiments were performed on a mediumspeed diesel engine, and these experiments verified the validity of the simulation model under different operating conditions. Finally, the impact of diesel/ethanol blended fuel on engine combustion and emission characteristics were investigated at different loads (25\%,50\%, and 100\%) and blending ratios (D100, D95E5, D90E10, D85E15, and D80E20) on diesel/ethanol blended fuels with a high ethanol blending ratio.

\section{Materials and Methods}

\subsection{Mathematical Model}

The commercial computational fluid dynamics (CFD) software CONVERGE is used to numerically simulate a diesel engine. CONVERGE automatically generates high-quality grids and using this software saves time and research costs. CONVERGE has a variety of geometric, fluid, and chemical solvers and provides a variety of options for important submodels such as spray, combustion, turbulence, and emissions. CONVERGE can calculate the engine combustion and emission performance accurately and numerically simulate internal combustion engines. 


\subsubsection{Turbulence Model}

There is a complex turbulent environment inside the cylinder of an internal combustion engine. The presence of turbulence increases the thickness of the flame and the combustion and heat release speed [36]. The RNG (Re-normalization group) $k-\varepsilon$ model and the wall function model for turbulent flow were used to numerically predict the heat transfer through the boundary [37]. The expression is as follows [38]:

$$
\begin{gathered}
\frac{\partial\left(\rho k_{t}\right)}{\partial t}+\operatorname{div}(\rho k U)=\operatorname{div}\left[\alpha_{k} \mu_{e f f} \operatorname{grad} k_{t}\right]+\tau_{i j} \cdot S_{i j}-\rho \varepsilon \\
\frac{\partial(\rho \varepsilon)}{\partial t}+\operatorname{div}(\rho \varepsilon U)=\operatorname{div}\left[a_{\varepsilon} \mu_{e f f} \operatorname{grad} \varepsilon\right]+C_{1 \varepsilon}^{*} \frac{\varepsilon}{k_{t}}-\tau_{i j} \cdot S_{i j}-C_{2 \varepsilon} \rho \frac{\varepsilon^{2}}{k_{t}}
\end{gathered}
$$

with

$$
\tau_{i j}=-\rho \overline{u_{i}^{\prime} u_{j}^{\prime}}=2 \mu_{t} S_{i j}-\frac{2}{3} \rho k_{t} \delta_{i j}
$$

and

$$
\begin{gathered}
\mu_{e f f}=\mu+\mu_{t} \mu_{t}=\rho C_{\mu} \frac{k_{t}^{2}}{\varepsilon} \\
C_{1 \varepsilon}^{*}=C_{1 \varepsilon}-\frac{\eta\left(1-\frac{\eta}{\eta_{0}}\right)}{1+\beta \eta^{3}} \eta=\frac{k_{t}}{\varepsilon} \sqrt{2 S_{i j} \cdot S_{i j}}
\end{gathered}
$$

where $\rho$ is the density, $\mathrm{g} / \mathrm{cm}^{3} ; k_{t}$ is the turbulent kinetic energy, $\mathrm{m}^{2} / \mathrm{s}^{2} ; U$ is the fluid velocity, $\mathrm{m} / \mathrm{s} ; S_{i j}$ is the turbulent source term; $\varepsilon$ is the turbulent dissipation rate; and $\mu$ is the molecular viscosity, Pa.s. The Kronecker delta $\delta_{i j}$ is provided by $\delta_{i j}=1$ if $i=j$ and $\delta_{i j}=0$ if $I \neq j . C_{1 \varepsilon}=1.42, C_{2 \varepsilon}=1.68, \alpha_{k}=\alpha_{\varepsilon}=1.39, C_{\mu}=0.0845, \eta_{0}=4.377, \beta=0.012$.

\subsubsection{Spray Breakup Model}

For the spray model, we selected the widely used KH-RT model in diesel spray. The spray comprises a liquid core area and a gas-liquid mixing area. The $\mathrm{KH}$ model describes the breaking phenomenon of the liquid core area, and the KH and RT models describe the breaking phenomenon of droplets in the gas-liquid mixing area [39]. The intact core or breakup length $L_{b}$ can be specified as [40]:

$$
L_{b}=C_{b l} \sqrt{\frac{\rho_{l}}{\rho_{g}}} d_{0}
$$

In the range of the broken length $L_{b}$, the crushing process is controlled by the $\mathrm{KH}$ crushing model. Outside the range of $L_{b}$, it is jointly described by the $\mathrm{KH}$ and RT models. At this point, CONVERGE first uses the RT model to control the droplet breakage; if the breakage cannot be achieved, the KH model is used [39].

$$
\tau_{K H}=\frac{B_{1}}{U} \sqrt{\frac{\rho_{1}}{\rho_{g}}} r_{0}
$$

\subsubsection{Combustion Model}

CONVERGE contains a variety of classic combustion models. In this article, we used the SAGE combustion model [41], which uses a set of input files in the CHEMKIN format to model detailed chemical kinetics. The SAGE combustion mode uses a chemical reaction mechanism including 68 species and 154 reactions. These 68 species contain species related to ethanol composition (including ethanol), and the 154 reaction species contain the oxidation reaction involved in ethanol. Different chemical mechanisms can describe the 
combustion of different fuels. According to Turns [42], a multi-step elementary reaction mechanism can be expressed as:

$$
\sum_{m=1}^{M} v_{m, i}^{\prime} x_{m}=\sum_{m=1}^{M} v_{m, i}^{\prime \prime} x_{m} \text { for } i=1,2, \ldots, I
$$

where $v_{m, i}^{\prime}$ and $v_{m, i}^{\prime \prime}$ are the stoichiometric coefficients for the reactants and products for species $m$ and reaction $i$, respectively; $I$ is the total number of reactions; and $x_{m}$ is the chemical symbol for species $m$. The net production rate of species $\omega_{m}$ is provided by:

$$
\dot{\omega}_{m}=\sum_{i=1}^{I} v_{m, i} q_{i} \text { for } m=1,2, \ldots, M
$$

where $M$ is the total number of species and

$$
v_{m, i}=v_{m, i}^{\prime \prime}-v_{m, i}^{\prime}
$$

The reaction rate parameter $q_{i}$ of the $i$ th reaction is

$$
q_{i}=k_{i, f} \prod_{m=1}^{M}\left[X_{m}\right]^{v_{m, i}^{\prime}}-k_{i, r} \prod_{m=1}^{M}\left[X_{m}\right]^{v_{m, i}^{\prime \prime}}
$$

where [Xm] is the molar concentration of species $m$, and $k_{i, f}$ and $k_{i, r}$ are the forward and reverse rate coefficients for reaction $i$. In SAGE, the forward rate coefficient is expressed in the Arrhenius form as:

$$
k_{i, f}=A_{i} T^{\beta i} \exp \left(\frac{-E_{i}}{R T}\right)
$$

where $A_{i}$ is the pre-exponential factor; $\beta_{i}$ is the temperature exponent; $E_{i}$ is the activation energy, cal $/ \mathrm{mol} ; R$ is the ideal gas constant; and $T$ is the temperature, $K$. In addition, the reverse rate coefficient can be specified in an analogous fashion as in Equation (12), or calculated from the equilibrium coefficient $K_{i, c}$ as:

$$
K_{i, c}=\frac{k_{i, f}}{k_{i, r}}
$$

The equilibrium coefficient $K_{i, c}$ is determined by thermodynamic properties,

$$
K_{i, c}=K_{i, p}\left(\frac{P_{a t m}}{R T}\right)^{\sum_{m=1}^{M} u_{m, i}}
$$

where $P_{a t m}$ is the atmospheric pressure, Pa. The equilibrium constant $K_{i, p}$ is obtained via

$$
K_{i, p}=\exp \left(\frac{\Delta S_{i}^{1}}{R}-\frac{\Delta H_{i}^{1}}{R T}\right)
$$

The $\Delta$ refers to the change that occurs in passing completely from reactants to products in the $i$ th reaction, specifically

$$
\begin{aligned}
\frac{\Delta S_{i}^{1}}{R} & =\sum_{m=1}^{M} u_{m, i} \frac{S_{m}^{1}}{R} \\
\frac{\Delta H_{i}^{1}}{R T} & =\sum_{m=1}^{M} u_{m, i} \frac{H_{m}^{1}}{R T}
\end{aligned}
$$

where $S_{d e}$ denotes entropy, $\mathrm{J} /(\mathrm{mol} \cdot \mathrm{K}) ;$ and $H_{d e}$ denotes enthalpy, $\mathrm{kJ} / \mathrm{mol}$. 


\subsection{4. $\mathrm{NO}_{\mathrm{x}}$ Model}

According to the working process characteristics of the internal combustion engine cylinder, it is generally believed that thermal $\mathrm{NO}$ is the main source of $\mathrm{NO}_{\mathrm{x}}$. The classic thermodynamic NO generation mechanism is the Zeldovich mechanism [43]. Afterward, a reaction path of a hydroxyl group reacting with a nitrogen atom to generate NO is added to form an extended Zeldovich mechanism. This mechanism is expressed by the following three reactions:

$$
\begin{aligned}
& \mathrm{O}+\mathrm{N}_{2} \Leftrightarrow \mathrm{NO}+\mathrm{N} \\
& \mathrm{O}_{2}+\mathrm{N} \Leftrightarrow \mathrm{NO}+\mathrm{O} \\
& \mathrm{OH}+\mathrm{N} \Leftrightarrow \mathrm{NO}+\mathrm{H} \\
& 2 \mathrm{NO}+\mathrm{O}_{2} \Leftrightarrow 2 \mathrm{NO}_{2}
\end{aligned}
$$

\subsubsection{Soot Model}

Hydrocarbon fuel undergoes a series of physical and chemical processes under high temperature and oxygen deficiency conditions to form soot particles; however, most of the soot will be oxidized before the exhaust valve opens. Developed according to the cylinder's soot generation and oxidation characteristics, a simple empirical model has been successfully used in predicting soot emission from internal combustion engines. This soot model was used in CONVERGE as a semiempirical two-step model. The net generation rate of soot is described as [44]:

$$
\frac{d M_{\text {soot }}}{d t}=\frac{d M_{a e}}{d t}-\frac{d M_{s o}}{d t}
$$

where $M_{\text {soot }}$ is the total amount of soot, $\mathrm{kg} ; M_{a e}$ is the amount of soot generation, $\mathrm{kg}$; and $M_{s o}$ is the amount of soot oxidation, $\mathrm{kg}$. The soot generation rate model is shown as follows [44]:

$$
\frac{d M_{s f}}{d t}=A_{f} p_{p}^{0.5} \exp \left(-\frac{E_{a e}}{R T}\right) \cdot M_{f v}
$$

where $A_{f}$ refers to the former factor; $p_{p}$ is the pressure; $E_{a e}$ is the activation energy; and $M_{f v}$ is the quality of fuel vapor. Acetylene $\left(\mathrm{C}_{2} \mathrm{H}_{2}\right)$, the precursor of soot, is generally used instead of fuel vapor when the chemical reaction mechanism simulates the ignition and combustion process [44].

\subsection{Establishment of Simulation Model}

In this study, the one-dimensional simulation verification of the engine was conducted using AVL-BOOST to determine the initial conditions of the engine. The three-dimensional CFD model of the diesel engine was created in CONVERGE according to the actual shape of the diesel engine. The 3-D CFD simulation model of cylinder is shown in Figure 1. 


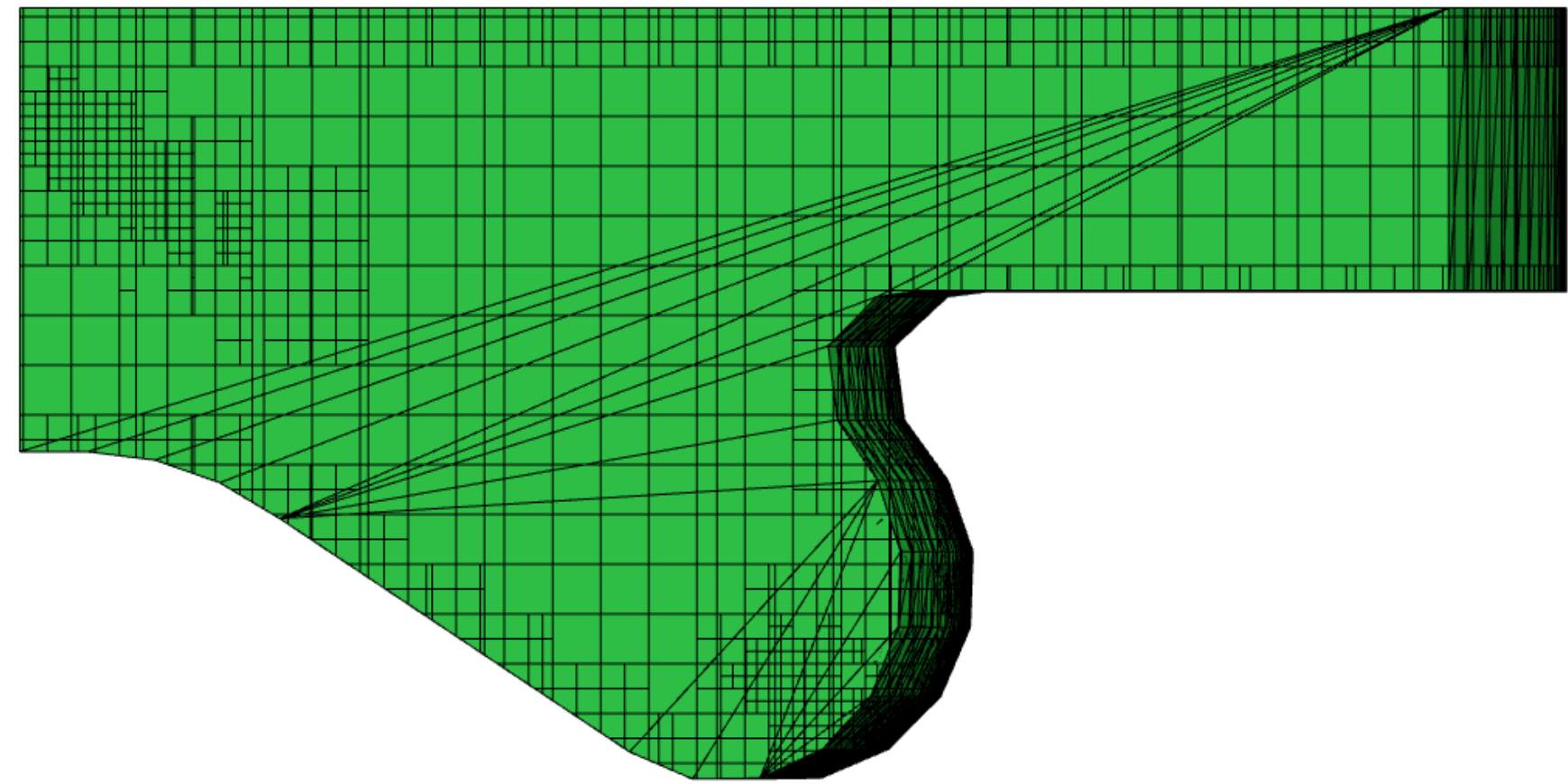

Figure 1. The geometric model of the combustion chamber in CONVERGE environment.

\subsection{Computational Mesh}

According to the geometry of the four-cylinder four-stroke Marine diesel engine block, a dynamic mesh is generated by the symmetrical distribution of eight nozzle holes. Fine mesh partitioning ensures that the model can accurately predict droplet breakage and evaporation. Figure 2 shows the cylinder pressure generated by three grid models when pure diesel is fully loaded. There is no significant difference in-cylinder pressure between the thin and medium grilles. Since the intermediate grid guarantees calculation accuracy and saves calculation time, the optimal intermediate grid was selected. The intermediate grid was considered the best solution for this study.

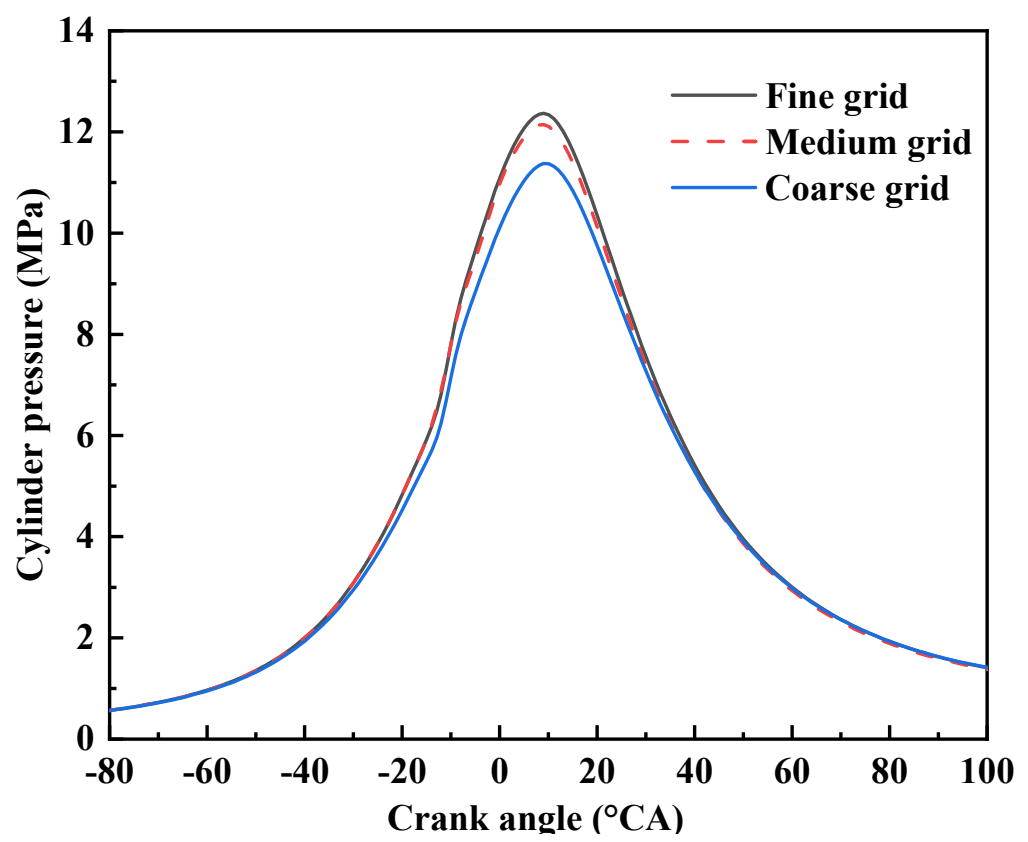

Figure 2. Comparison between in-cylinder pressure curves of different basic grids. 


\section{Experimental Cases and Engine Setup}

\subsection{Fuel Properties}

Diesel and ethanol were used in this study. Diesel/ethanol blended fuels were formed by blending different ratios of ethanol into diesel fuel, and their combustion and emission characteristics were analyzed. The fuel properties are shown in Table 1. In this article, D100 represents pure diesel, D95E5 represents 95\% diesel and 5\% ethanol, D90E10 represents $90 \%$ diesel and 10\% ethanol, D85E15 represents 85\% diesel and 15\% ethanol, and D80E20 represents $80 \%$ diesel and $20 \%$ ethanol.

Table 1. The properties of diesel/ethanol blended fuel.

\begin{tabular}{ccc}
\hline Fuel & Diesel & Ethanol \\
\hline Chemical formula & - & $\mathrm{C}_{2} \mathrm{H}_{5} \mathrm{OH}$ \\
Boiling temperature $\left({ }^{\circ} \mathrm{C}\right)$ & $190-280$ & 64.7 \\
Oxygen volume fraction $(\%)$ & 0.0 & 34.7 \\
Density $\left(\mathrm{g} / \mathrm{m}^{3}\right.$, at $\left.20^{\circ} \mathrm{C}\right)$ & $0.82-0.86$ & 0.79 \\
Viscosity $\left(\mathrm{MPa} \cdot \mathrm{s}\right.$, at $\left.20^{\circ} \mathrm{C}\right)$ & $3.0-8.0$ & 1.2 \\
Flash point $\left({ }^{\circ} \mathrm{C}\right)$ & $65-88$ & $13-14$ \\
Cetane number $(\mathrm{CN})$ & $45-65$ & 8 \\
Low calorific value $\left(\mathrm{MJ} \cdot \mathrm{kg}^{-1}\right)$ & $42.5-42.8$ & 26.8 \\
\hline
\end{tabular}

\subsection{Engine Specifications}

The test was conducted on a marine medium-speed diesel engine. The main parameters of the diesel engine are shown in Table 2. The schematic diagram of the experimental system is shown in Figure 3.

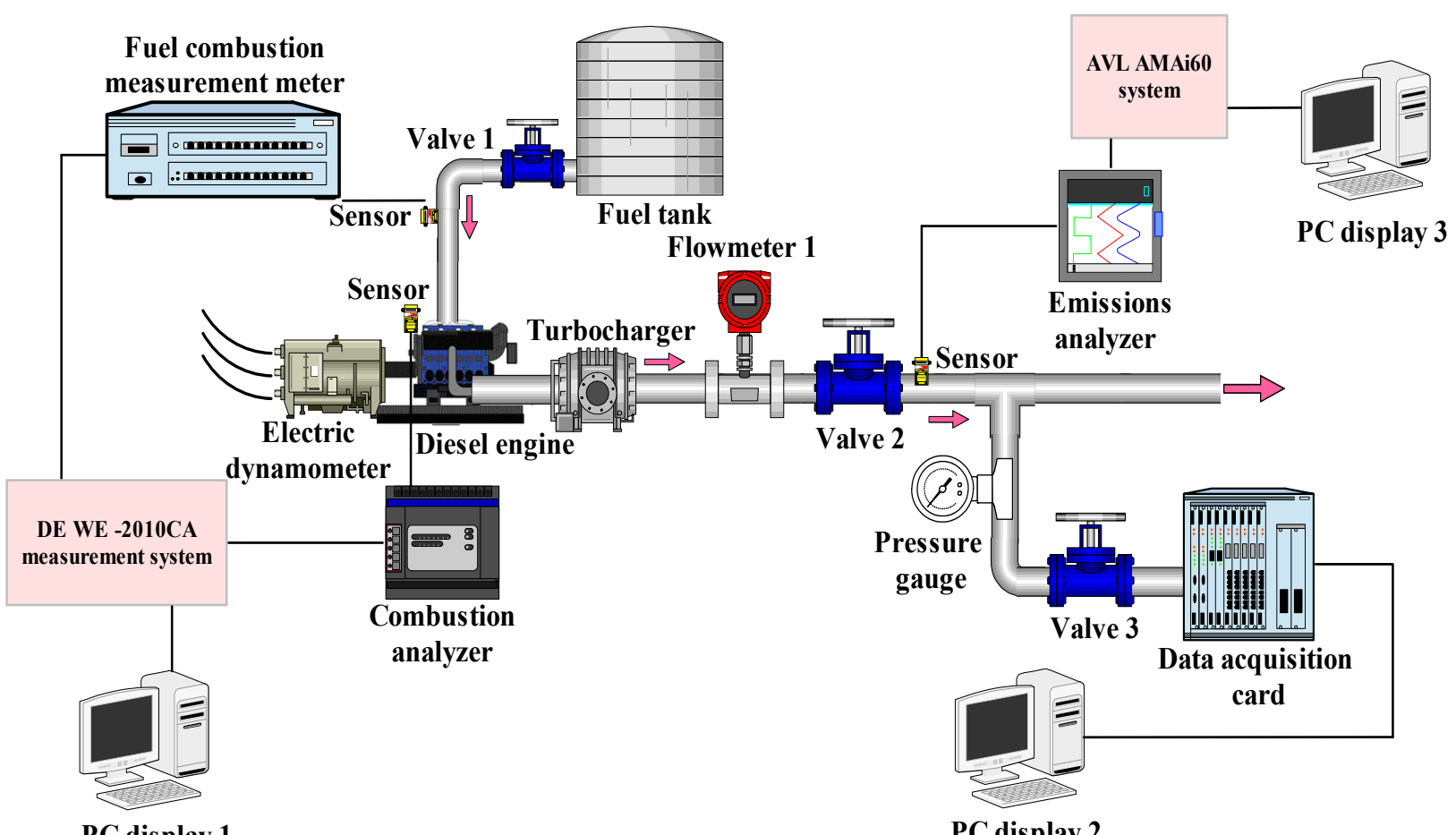

Figure 3. Schematic diagram of engine test. 
Table 2. Engine specifications and boundary conditions.

\begin{tabular}{cccc}
\hline Type & Value & Type & Value \\
\hline Bore $\times$ stroke $(\mathrm{mm})$ & $190 \times 210$ & Compression ratio & 14 \\
Number of cylinders & 4 & Head temperature $(\mathrm{K})$ & 553 \\
Engine speed $(\mathrm{rpm})$ & 2000 & Piston temperature $(\mathrm{K})$ & 423 \\
Effective power $(\mathrm{kW})$ & 220 & Wall temperature $(\mathrm{K})$ & 433 \\
Nozzle radius $(\mathrm{mm})$ & 0.26 & Temperature at IVC $(\mathrm{K})$ & 341 \\
Fuel injection holes & 8 & Pressure at IVC $(\mathrm{bar})$ & 1.97 \\
Cylinder diameter $(\mathrm{MPa})$ & 2.05 & Turbulent kinetic energy $\left(\mathrm{m}^{2} / \mathrm{s}^{2}\right)$ & 62.0271 \\
Connecting rod $(\mathrm{mm})$ & 410 & Turbulent dissipation $\left(\mathrm{m}^{2} / \mathrm{s}^{3}\right)$ & $17,183.4$ \\
\hline
\end{tabular}

Total uncertainty of experiment $=$ Square root of [(uncertainty of pressure sensor $)^{2}$

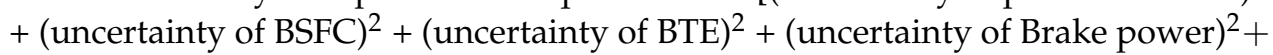
(uncertainty of $\mathrm{NO}_{\mathrm{x}}$ emission) $)^{2}+(\text { uncertainty of } \mathrm{CO} \text { emission) })^{2}+$ (uncertainty of $^{2}$ Soot emission $\left.)^{2}\right]=$ Square $\operatorname{root}$ of $\left[(1.5 \%)^{2}+(1.7 \%)^{2}+(0.53 \%)^{2}+(0.3 \%)^{2}+(0.53 \%)^{2}+\right.$ $\left.(0.32 \%)^{2}+(2.8 \%)^{2}\right]=3.706 \%$

\subsection{Uncertainty Analysis}

Generally, experimental measurement results contain some errors and uncertainties [45]. The uncertainty of experimental results is caused by the selection, observation, and calibration of sensors. The measurement results are used to calculate the required experimental results. The uncertainty percentage of parameters such as BSFC, BTE, and $\mathrm{NO}_{\mathrm{x}}$ can be obtained from Equation (24). The $R$ in Equation (25) is a function of the independent variables $I_{1}, I_{2}, \ldots, I_{n}$. In Equation $(24), u_{1}, u_{2}, \ldots, u_{n}$ represents uncertainty in the independent variable and $U_{R}$ represents uncertainty in the result.

$$
\begin{gathered}
U_{R}=\left\{\left[\left(\partial R / \partial I_{1}\right) u_{1}\right]^{2}+\left[\left(\partial R / \partial I_{2}\right) u_{2}\right]^{2}+\cdots+\left[\left(\partial R / \partial I_{n}\right) u_{n}\right]^{2}\right\}^{1 / 2} \\
R=\left\{I_{1}, I_{2}, I_{3}, \cdots I_{n}\right\}
\end{gathered}
$$

The measuring range and accuracy of the measuring equipment we used in this article are shown in Table 3 . The following equation was used to calculate the total experimental uncertainty.

Table 3. Uncertainty of measured parameters.

\begin{tabular}{cccc}
\hline Measurements. & Measuring Range & Accuracy & Uncertainty (\%) \\
\hline Engine speed & $1-2000 \mathrm{rpm}$ & $\pm 0.2 \%$ & \pm 0.24 \\
Pressure sensor & $0-25 \mathrm{MPa}$ & $\pm 10 \mathrm{kPa}$ & \pm 0.5 \\
Exhaust gas temperature & $0-1000^{\circ} \mathrm{C}$ & $\pm 1{ }^{\circ} \mathrm{C}$ & \pm 0.25 \\
NOx emission & $0-5000 \mathrm{ppm}$ & $\pm 10 \mathrm{ppm}$ & \pm 0.53 \\
CO emission & $0-10 \% \mathrm{vol}$ & $\pm 0.03 \%$ & \pm 0.32 \\
Soot emission & $0-9 \mathrm{FSN}$ & $\pm 0.1 \mathrm{FSN}$ & \pm 2.8 \\
BSFC & - & $\pm 5 \mathrm{~g} / \mathrm{kW} \cdot \mathrm{h}$ & \pm 1.5 \\
BTE & - & $\pm 0.5 \%$ & \pm 1.7 \\
Brake power & - & $\pm 0.03 \mathrm{~kW}$ & \pm 0.3 \\
Air flow rate & $0-33.3 \mathrm{~kg} / \mathrm{min}$ & $\pm 1 \%$ & \pm 0.5 \\
Fuel flow rate & $0.5-100 \mathrm{~L} / \mathrm{h}$ & $\pm 0.04 \mathrm{~L} / \mathrm{h}$ & \pm 0.5 \\
\hline
\end{tabular}

\subsection{Model Validation}

In order to verify the accuracy of the model, the simulation results were compared to the experimental results. During the experiment, an exhaust gas analyzer (Horiba MEXA-1600) was used to measure the generated nitrogen oxide with an error of $1 \%$. A fuel consumption meter (FCMM-2) was used to measure the brake specific fuel consumption. 
A combustion analyzer (DEWE-2010CA) was used to monitor the diesel engine's combustion. An Opacimeter (AVL Dismoke-4000) was used to measure the smoke generated. The EFS-IFR600 was used to measure the fuel injection rate with a measurement error of $0.5 \%$. A hydraulic dynamometer was used to measure the load of the diesel engine. An electronic control unit (ECU) system was used to control the electronically controlled diesel engine. In addition, appropriate sensors were used to measure temperature, flow, and pressure. Detailed specifications for the main measuring instruments are shown in Table 4.

Table 4. Specifications of main measuring instruments.

\begin{tabular}{cccc}
\hline Item & Content & Accuracy & Uncertainty (\%) \\
\hline Electric dynamometer & NIDY S22-2/0525-1BV-1 & Torque: $\pm 0.5 \%$ F.S; Speed: $\pm 1 \mathrm{r} / \mathrm{min}$ & \pm 0.2 \\
Dynamometer control system & PUMA OPEN1.4.1 & $\pm 0.5 \%$ F.S & \pm 0.2 \\
Air flowmeter & TOCEIL 20N125 & $\pm 1 \%$ & \pm 0.15 \\
Diesel flowmeter & TOCEIL CMFG010 & $0.11 \%$ & \pm 0.15 \\
Temperature sensor & Thermojunction type & $\pm 0.5{ }^{\circ}$ C & \pm 0.15 \\
Pressure sensor & Piezoresistance type & $\pm 0.5 \%$ F.S & \pm 0.5 \\
Emissions analyzer & AVL AMAi60 & $/$ & \pm 0.25 \\
Combustion analyzer & DEWE-2010CA & $\pm 0.5 \%$ & \pm 0.25 \\
Injection measuring & EFS-IFR600 & & \pm 0.5 \\
instrument & & & \\
\hline
\end{tabular}

The experiment was conducted on a four-cylinder four-stroke diesel engine. Tests were conducted at $200 \mathrm{rpm}$ for $50 \%$ and $100 \%$ loads, respectively. The diesel engine was fueled with D90E10 blended fuel. The experimental results and simulation results are shown in Figure 4. As seen in Figure 4, the error between the experimental results and the simulation results is minor at less than $5 \%$. Therefore, the model can accurately predict the combustion and emission characteristics of diesel engines.
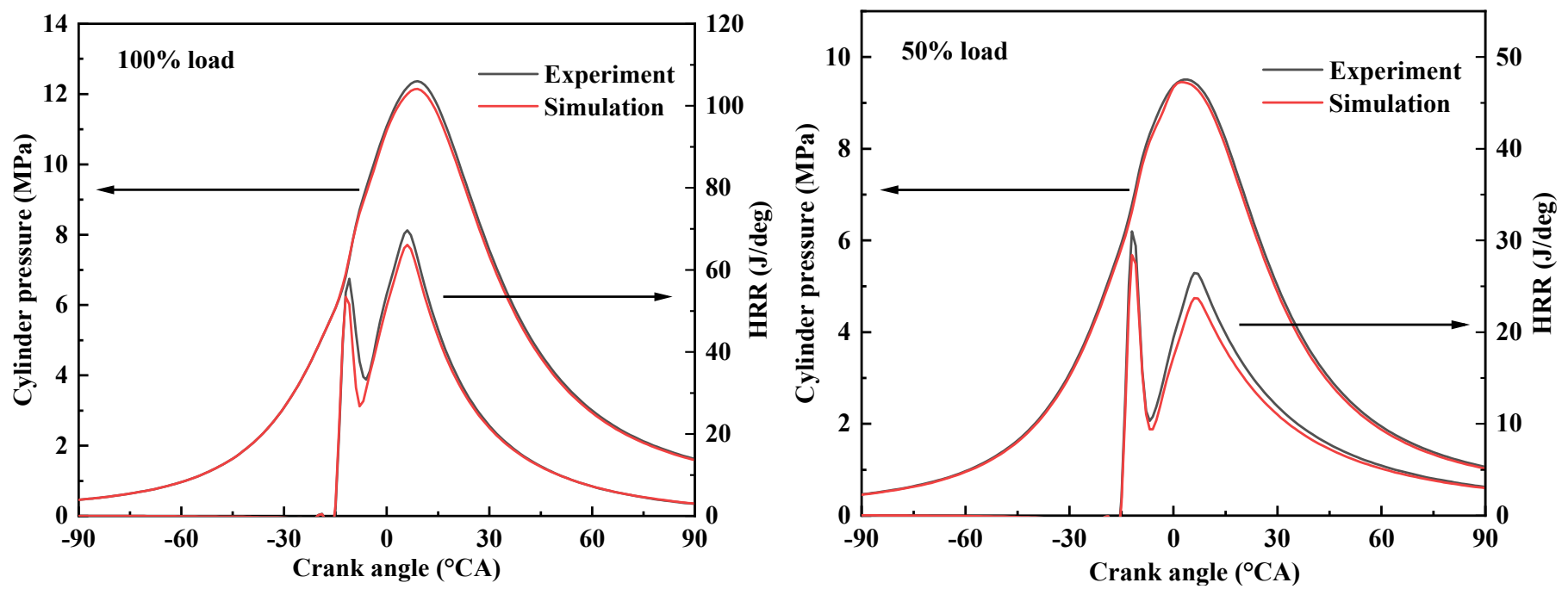

Figure 4. Comparison between experimental and simulation results of engine cylinder pressure and heat release rate.

\section{Results and Discussion}

\subsection{Engine Combustion Performance}

\subsubsection{Cylinder Pressure}

Figure 5 shows the effects of diesel/ethanol blended fuel with different blending ratios on the engine's cylinder pressure at different loads (including 100\% load (see Figure 5a), $50 \%$ load (see Figure 5b), 25\% load (see Figure 5c)). The cylinder pressure of D80E20 is the 
highest, followed by D85E15, D90E10, D95E5, and D100. As the ethanol ratio increases in the blended fuel, the cylinder's maximum combustion pressure increases gradually. For example, when the ethanol ratio in the blended fuel increases to $20 \%$, the cylinder pressure increases by $0.46 \%$ because the cetane number of ethanol is low, leading to the extension of the mixed fuel's ignition delay period, the delay of the ignition time, and the increase in the mixture amount formed during the ignition delay period. In addition, ethanol is an oxygenated fuel that provides more oxygen while participating in the incylinder combustion reaction and effectively promotes combustion. Therefore, the pressure in the cylinder increases. Similar conclusions were drawn by Liang et al. [15] and Chen et al. [7].
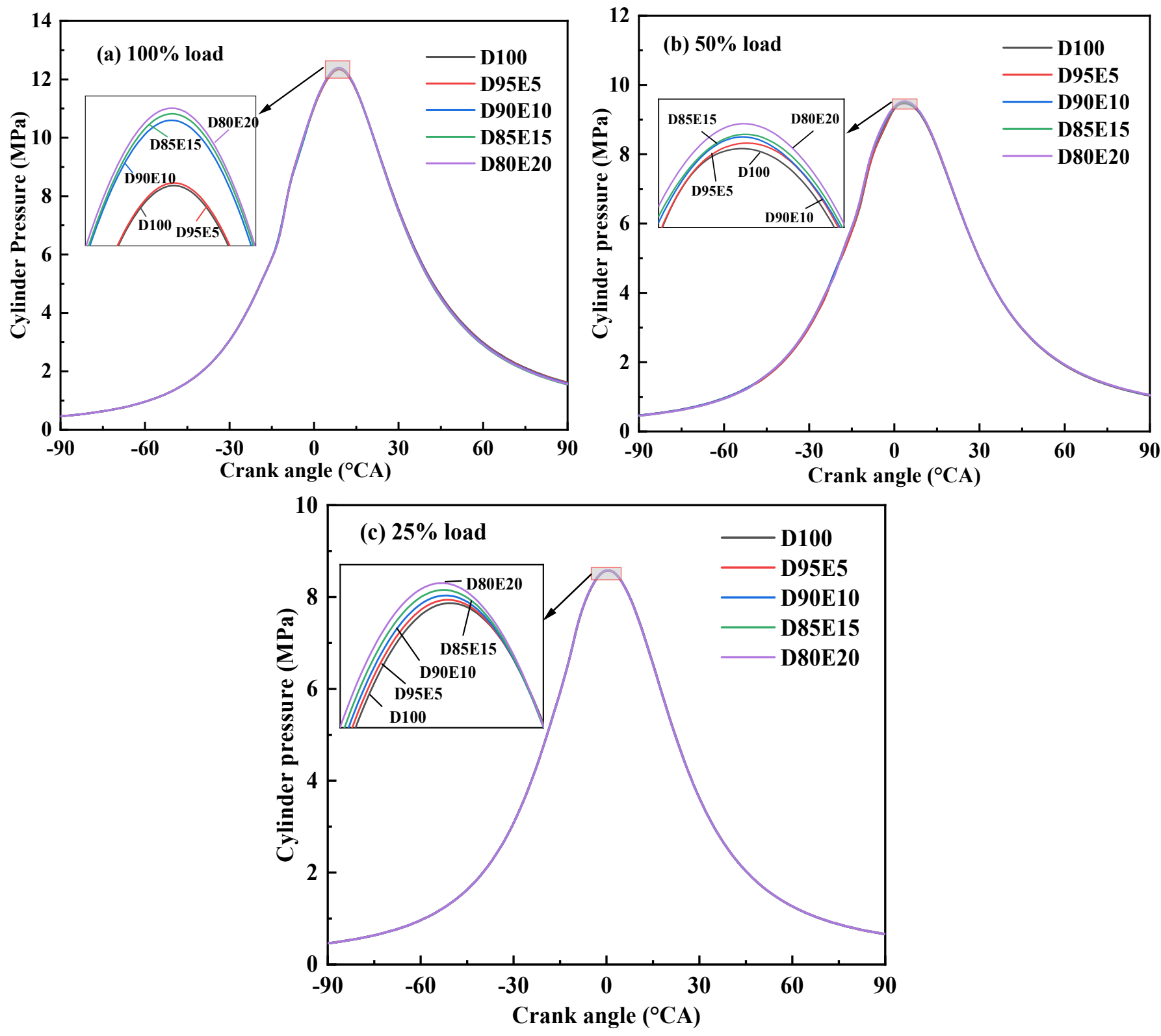

Figure 5. Effects of diesel/ethanol blended fuels with different blending ratios on cylinder pressure under different loading conditions.

\subsubsection{Cylinder Temperature}

Figure 6 shows the effects of diesel/ethanol blended fuel with different blending ratios on the engine's cylinder temperature at different loads (including 100\% load (see Figure 6a), $50 \%$ load (see Figure 6b), 25\% load (see Figure 6c)). As the ratio of ethanol in the blended 
fuel increases, the maximum cylinder temperature also increases. When the ethanol ratio in the blended fuel increases to $5 \%, 10 \%, 15 \%$, and $20 \%$, the peak temperature of the cylinder becomes $0.28 \%, 0.52 \%, 0.65 \%$, and $0.94 \%$ higher than diesel, respectively; the main reason for this is that ethanol is an oxygenated fuel. As the ethanol ratio increases, the oxygen content of blended fuel also increases, and the decrease in viscosity can better facilitate the atomization of fuel into the combustion chamber. Simultaneously, the higher oxygen content increases the combustion rate of blended fuel, improving the intensity of premixed combustion, and sufficient combustion. Therefore, the cylinder temperature increases. Zhang et al. [35] drew similar conclusions.
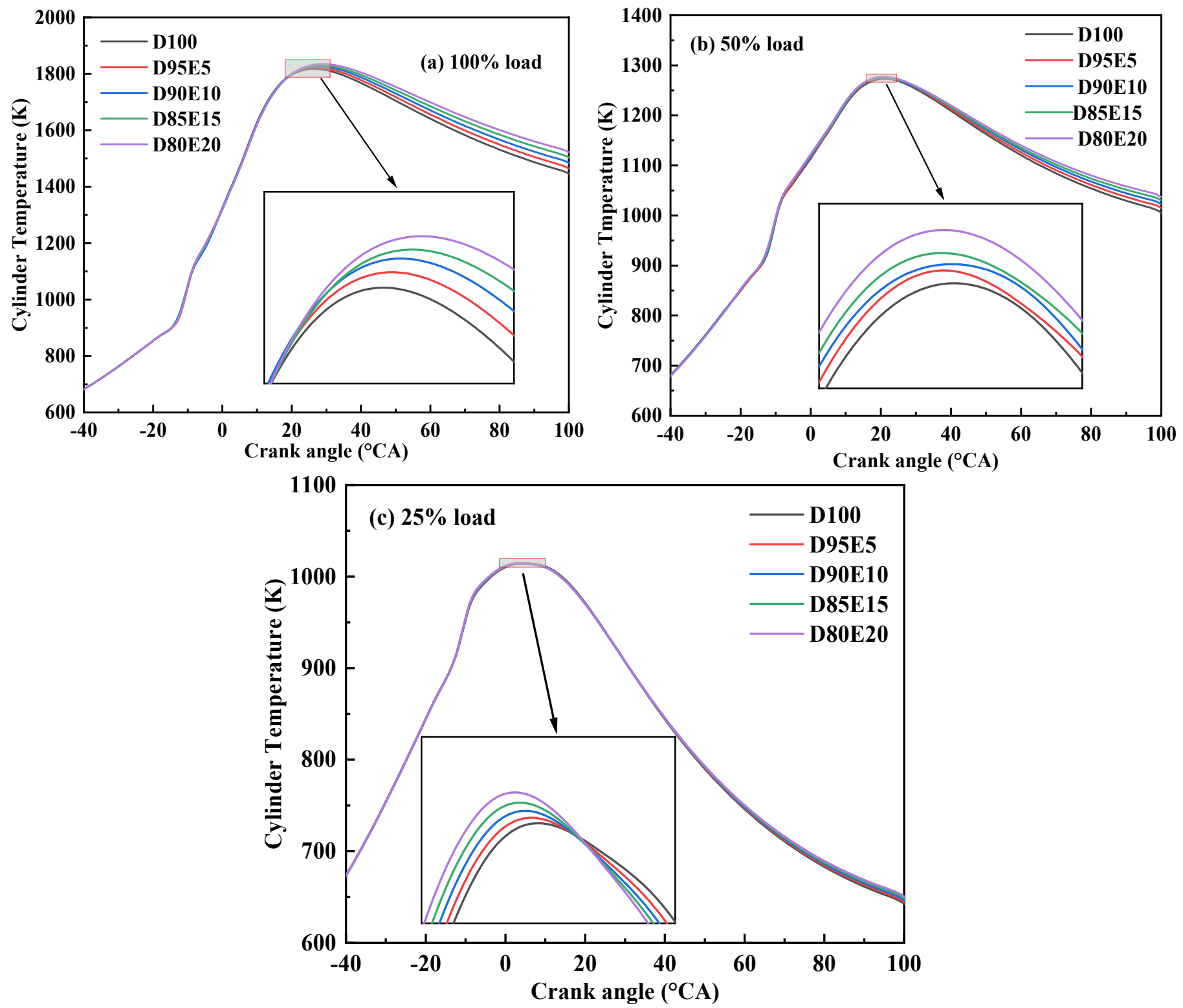

Figure 6. Effects of diesel/ethanol blended fuels with different blending ratios on temperature under different loading conditions.

Figure 7 shows the distribution field of the temperature in-cylinder at $100 \%$ load. Compared with D100, diesel/ethanol blended fuel produces more high-temperature areas because ethanol's lower density and surface tension promote fuel atomization and sufficient combustion. 


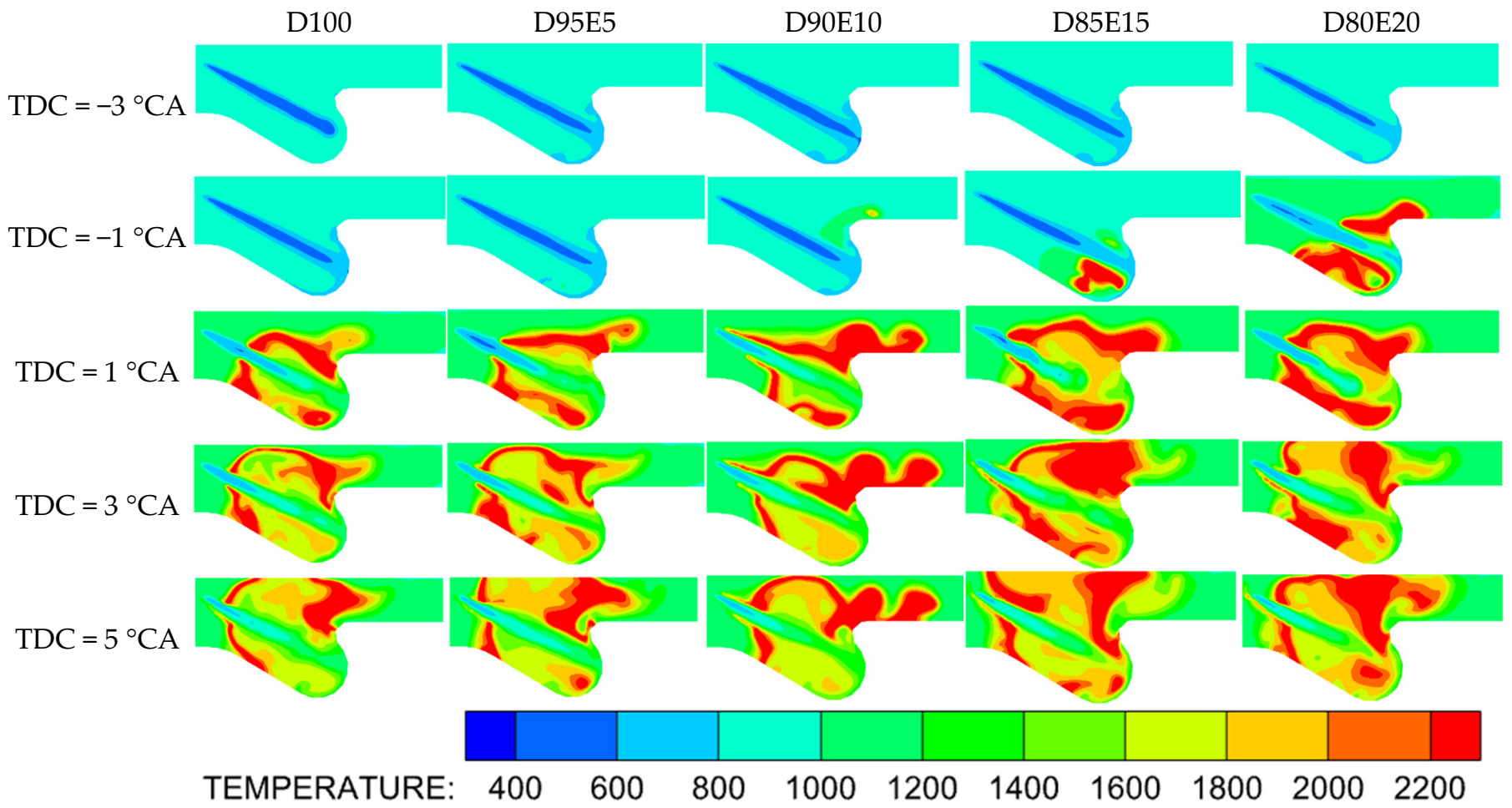

Figure 7. The distribution field of the temperature in-cylinder at $100 \%$ load. [K].

\subsubsection{Heat Release Rate}

Figure 8 shows the effects of diesel/ethanol blended fuel with different blending ratios on the engine's heat release rate(HRR) at different loads(including 100\% load (see Figure 8a), 50\% load (see Figure 8b), 25\% load (see Figure 8c)). The overall HRR of diesel/ethanol blended fuel increases as the ethanol blending ratio increases because of the low cetane number and high latent heat of vaporization in ethanol, which leads to a longer ignition delay period of the blended fuel, increases the amount of combustible mixture formed in the premixing stage, improves the engine combustion conditions, and allows the blended fuel to burn fully. Liu et al. [46] evaluated the effects of E0, E10, and E20 on the engine. Their conclusion also confirmed that HRR increases with the increase in ethanol ratio.

\subsection{Economic Performance}

\subsubsection{Brake Specific Fuel Consumption}

Brake specific fuel consumption (BSFC) is an important index for measuring the economic performance of an engine [47]. Figure 9a shows the effects of diesel/ethanol blended fuel with different blending ratios on the engine's BSFC at different loads. The diesel engine's fuel consumption gradually as the ethanol ratio increases in blended fuel. For example, when pure diesel is used at $25 \%$ load, the fuel consumption of the engine is $810.79 \mathrm{~g} /(\mathrm{kW} \cdot \mathrm{h})$. As the ethanol content in the blended fuel increases to $5 \%, 10 \%, 15 \%$, and $20 \%$, the fuel consumption increases to $820.22 /(\mathrm{kW} \cdot \mathrm{h}), 831.88 /(\mathrm{kW} \cdot \mathrm{h}), 842.76 /(\mathrm{kW} \cdot \mathrm{h})$, and $853.91 /(\mathrm{kW} \cdot \mathrm{h})$, respectively; this is because the calorific value of diesel fuel $(42.5 \mathrm{MJ} / \mathrm{kg})$ is higher than the calorific value of ethanol $(26.8 \mathrm{MJ} / \mathrm{kg})$, as shown in Table 1 . An increase in the ratio of ethanol in blended fuel reduces the total calorific value of blended fuel, leading to an increase in BSFC. 

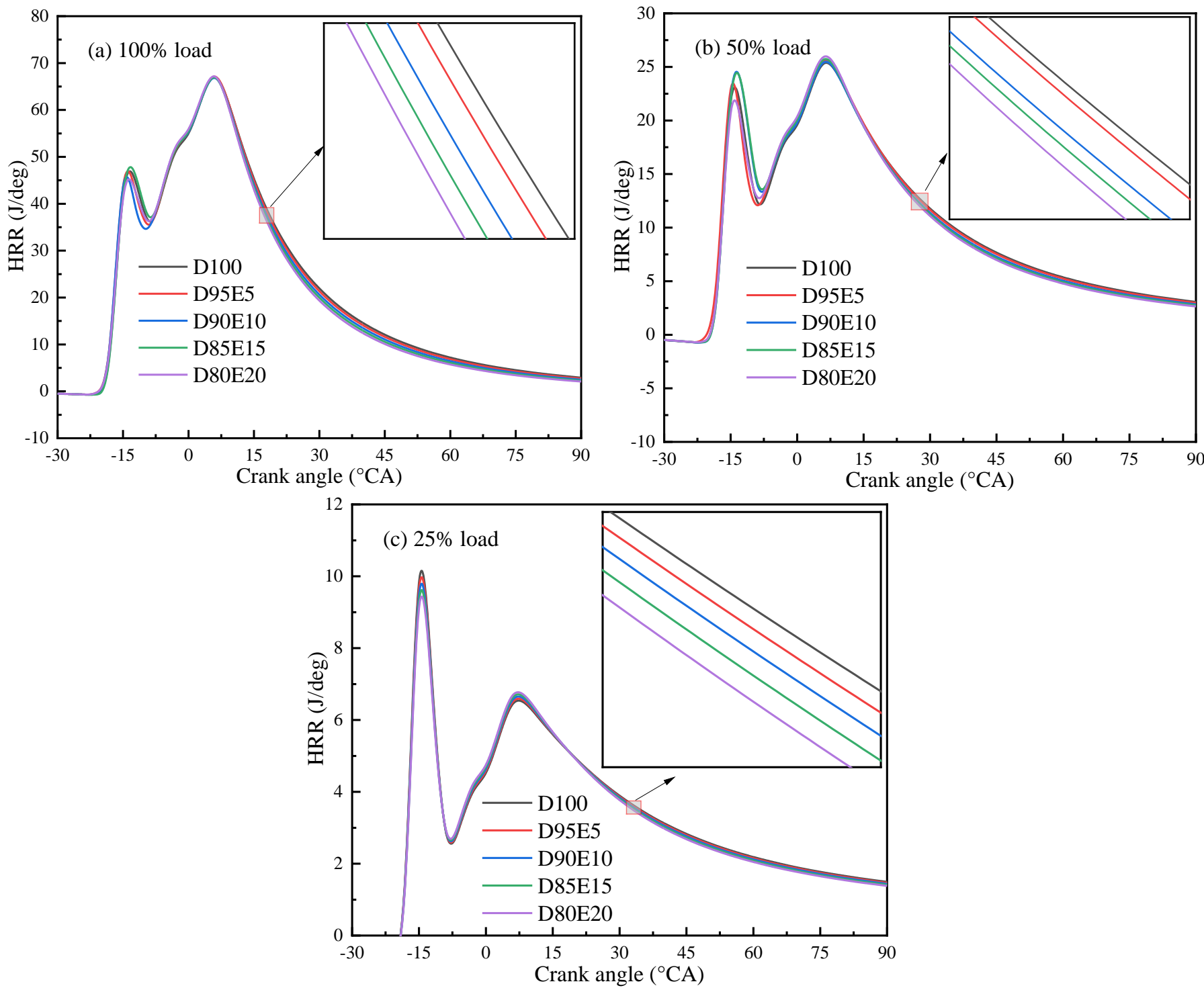

Figure 8. Effects of diesel/ethanol blended fuels with different blending ratios on HRR under different loading conditions.

\subsubsection{Brake Power}

Figure $9 \mathrm{~b}$ shows the effects of diesel/ethanol blended fuel with different blending ratios on the engine's brake power at different loads. The engine's power decreases gradually as the ethanol ratio increases in the blended fuel. Moreover, the higher the ethanol ratio is in the blended fuel, the more apparent the reduction in engine power. Compared with D100, the power of D95E5, D90E10, D85E15, and D80E20 blended fuel reduces by $0.96 \%, 1.97 \%, 2.99 \%$, and $4.12 \%$, respectively; this is because the calorific value of ethanol/diesel blended fuel is lower than D100, resulting in lower combustion power than diesel. 


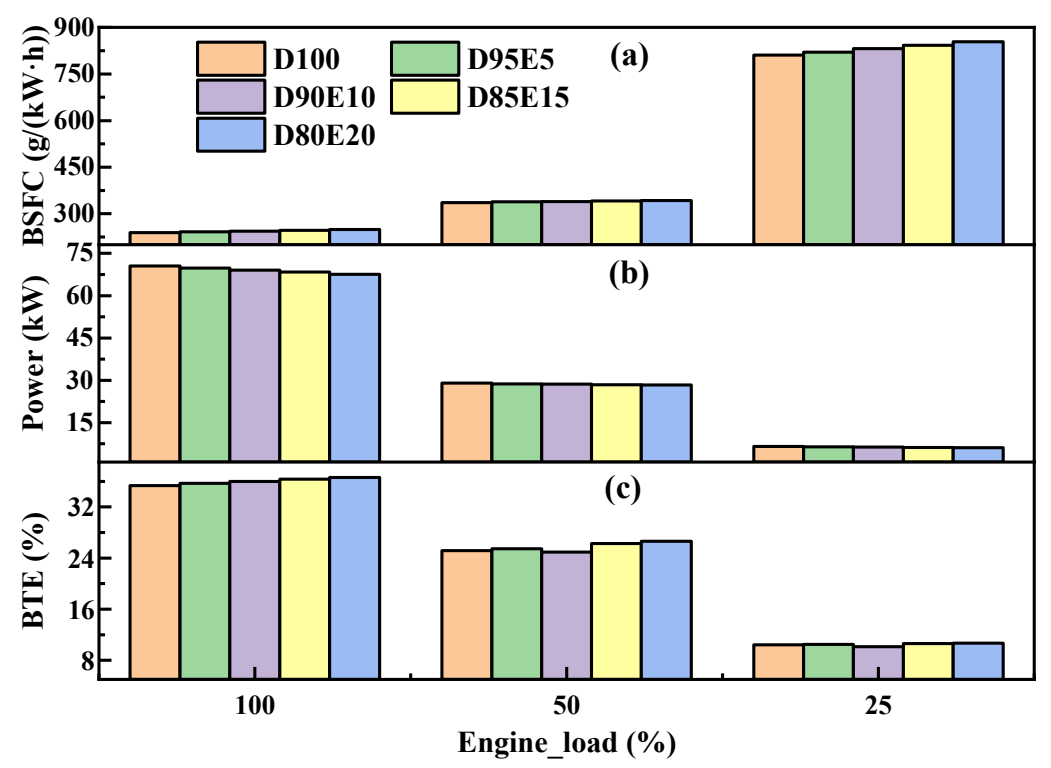

Figure 9. Effects of diesel/ethanol blended fuels with different blending ratios on (a) BSFC, (b) power, and (c) BTE under different loading conditions.

\subsubsection{Brake Thermal Efficiency}

Figure 9c shows the effects of diesel/ethanol blended fuel with different blending ratios on the engine's brake thermal efficiency (BTE) at different loads. BTE decreases with increased ethanol content at low loads and increases as the ethanol ratio increases at high loads because the increase in ethanol ratio in diesel/ethanol blended fuel improves the spray characteristics of the blended fuel. Since ethanol is an oxygenated fuel, it increases the oxygen content of the blended fuel, improving the combustion characteristics of the fuel, and further improving the BTE of the engine. Han et al. [48] investigated the dynamic characteristics of diesel/ethanol dual fuel engines and reached similar conclusions. They confirmed that the combustion efficiency and BTE of ethanol decreased under low load conditions in the dual fuel mode and increased under medium and high load conditions.

\subsection{Emission Performance \\ 4.3.1. $\mathrm{NO}_{\mathrm{x}}$ Emission}

Figure 9 shows the effects of diesel/ethanol blended fuel with different blending ratios on $\mathrm{NO}_{x}$ emission at different loads (including 100\% load (see Figure 9a), 50\% load (see Figure 9b), 25\% load (see Figure 9c)). $\mathrm{NO}_{\mathrm{x}}$ emission increases with increased engine load; because the increase in engine load leads to increased peak temperature, which improves the emission level of $\mathrm{NO}_{\mathrm{x}}$. In addition, the engine's $\mathrm{NO}_{\mathrm{x}}$ emission increases as the ethanol ratio increases in the blended fuel; this is because ethanol has low density, low viscosity, and high oxygen content characteristics, which improve combustion in the engine cylinder and produce more $\mathrm{NO}_{x}$ in the local high-temperature area. Compared with the cylinder temperature cloud diagram in Figure $10, \mathrm{NO}_{\mathbf{x}}$ generation is mainly affected by the temperature in the cylinder. The higher the temperature is, the more $\mathrm{NO}_{\mathrm{x}}$ emissions is, particularly in the concentrated temperature area. In addition, the cetane number of diesel/ethanol blended fuel is lower than D100, which leads to the extension of the ignition delay period, the increase of in-cylinder fuel injection, and premixed combustion, thereby increasing $\mathrm{NO}_{x}$ emission. Similar conclusions were drawn by Sayin et al. [49] and Alptekin et al. [50]. 

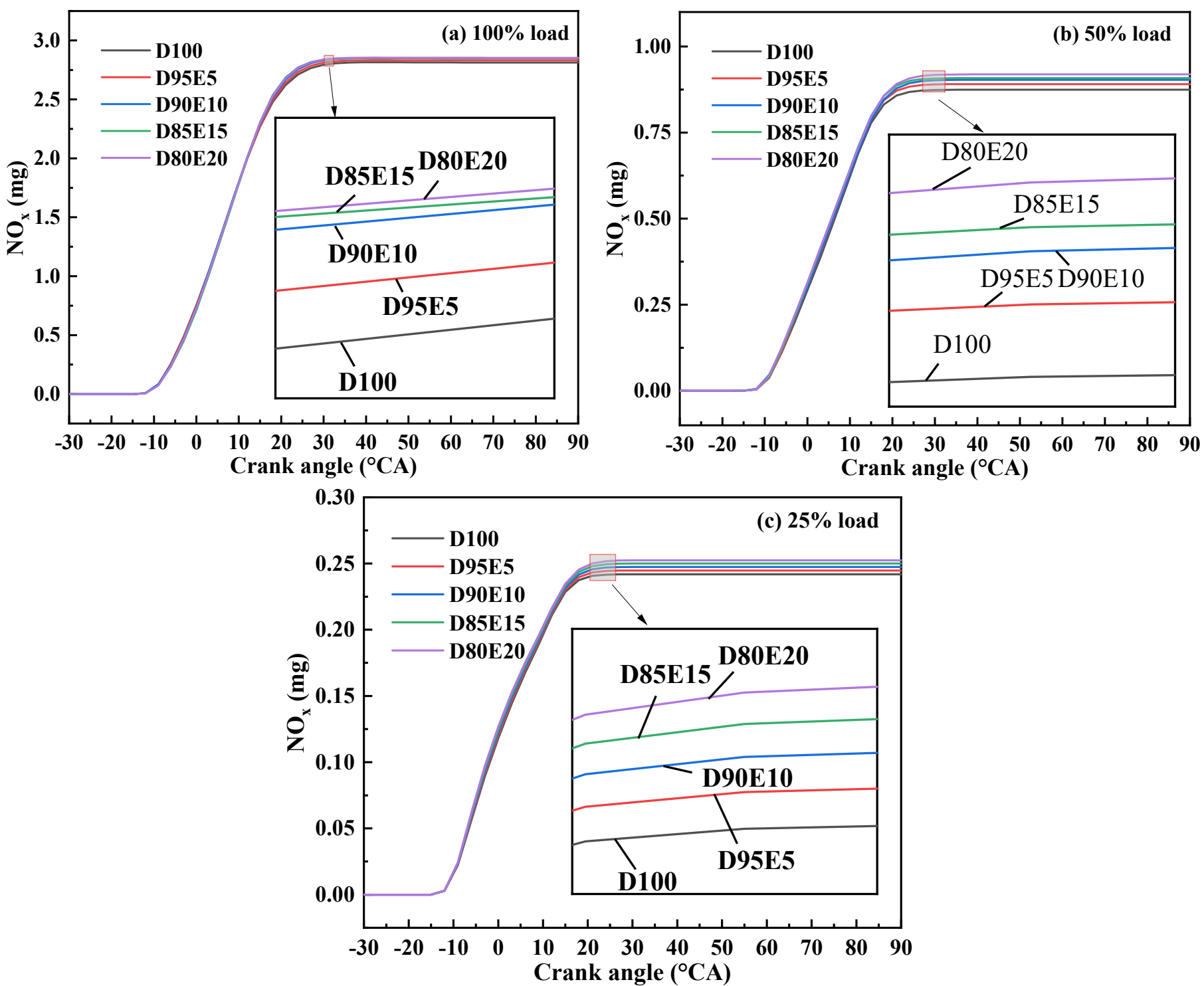

Figure 10. Effects of diesel/ethanol blended fuels with different blending ratios on $\mathrm{NO}_{\mathrm{x}}$ emission under different loading conditions.

\subsubsection{CO Emission}

Figure 11 shows the effects of diesel/ethanol blended fuel with different blending ratios on the engine's $\mathrm{CO}$ emission at different loads. Compared with pure diesel, $\mathrm{CO}$ emission increases with increased ethanol content at a low load. At high loads, $\mathrm{CO}$ emission decreases with increased ethanol content; this is because at low load, the anal temperature is low, and the latent vaporization heat of ethanol is higher than diesel, resulting in more heat absorption in the combustion process of blended fuel, difficult complete combustion, and increased $\mathrm{CO}$ emission (see Figure 12). There are large amounts of fuel injection per cycle at high loads and higher temperatures in the cylinder. As an oxygenated fuel, ethanol can provide additional oxygen during combustion, effectively improving the problem of insufficient oxygen in the cylinder, creating sufficient combustion, and inhibiting the generation of $\mathrm{CO}$. This observation is consistent with the conclusion of Le et al. [14]. 


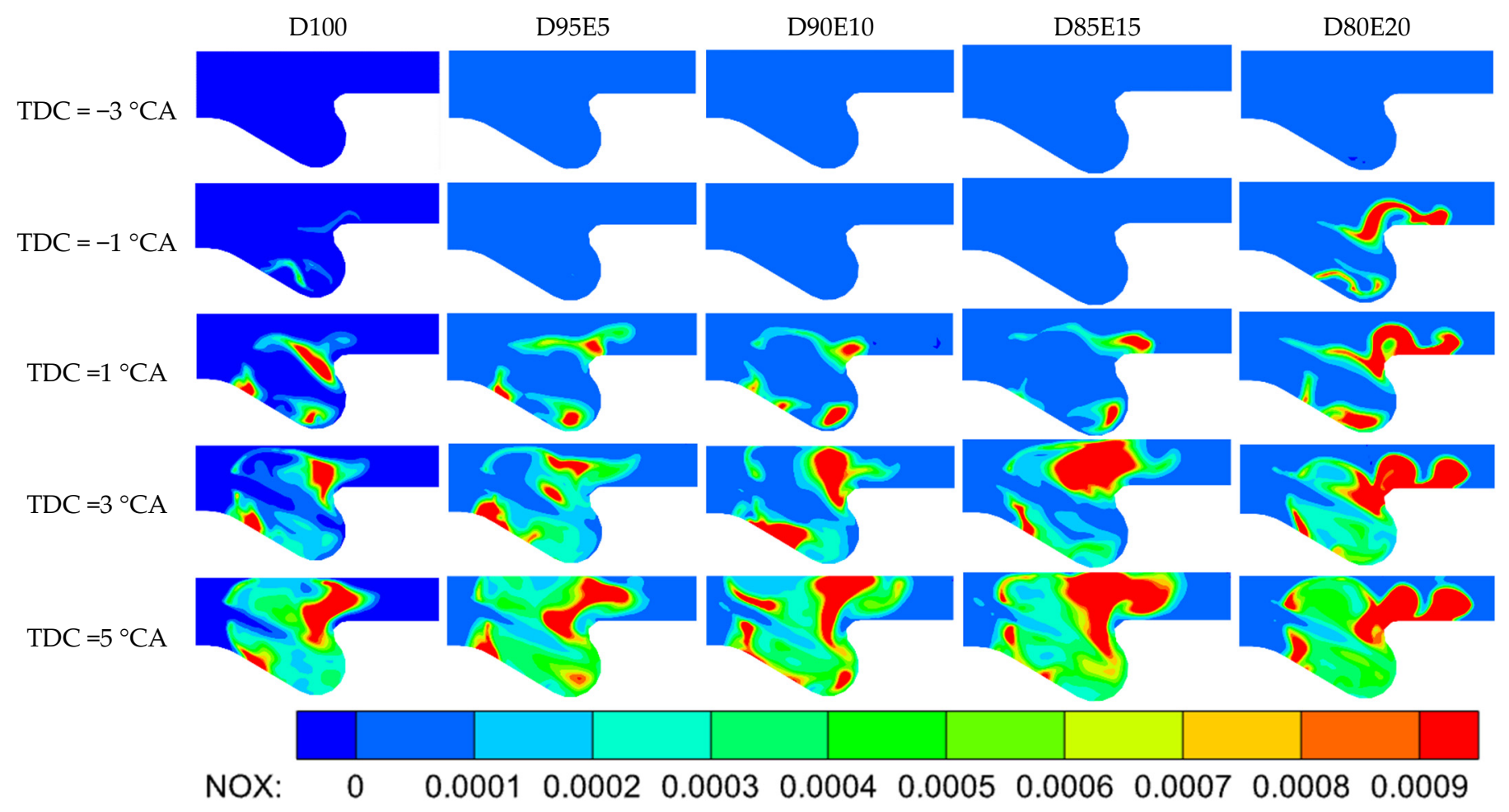

Figure 11. The $\mathrm{NO}_{\mathrm{x}}$ distribution field in the cylinder at $50 \%$ load $[\mathrm{g}]$.

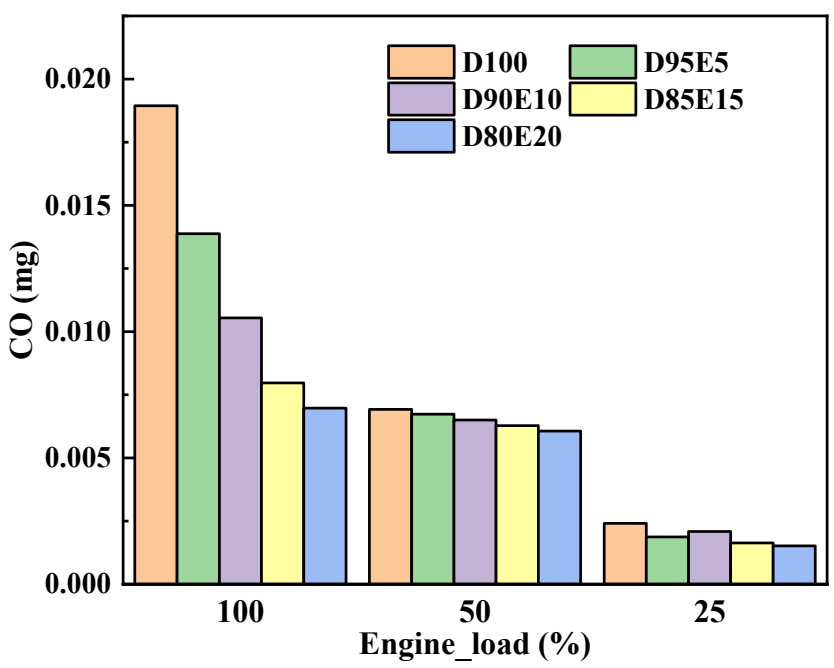

Figure 12. Effects of diesel/ethanol blended fuels with different blending ratios on $\mathrm{CO}$ emission under different loading conditions.

\subsubsection{Soot Emission}

Figure 13 shows the effects of diesel/ethanol blended fuel with different blending ratios on engine soot emissions at different loads (including 100\% load (see Figure 13a), $50 \%$ load (see Figure 13b), 25\% load (see Figure 13c)). Soot emission increases as the engine load increases because the oxygen in the cylinder is insufficient at higher loads and large amounts of soot form in the high-temperature anoxic area. In addition, soot emission decreases as the ethanol ratio increases in blended fuel. For example, under $100 \%$ load conditions, soot emission increases by $4.77 \%, 9.08 \%, 13.51 \%$, and $17.24 \%$ when the ethanol content in blended fuels increases to $5 \%, 10 \%, 15 \%$, and $20 \%$, respectively. This increase is mainly because the combustion temperature in the cylinder is higher at high loads, and 
the oil supply per cycle increases, enabling the formation of an over-concentrated mixture. At this time, the mitigation effects of ethanol on the local over-concentrated area in the cylinder and the combustion promotion effects of additional oxygen are more apparent and effectively reduce the soot emission under high load conditions.
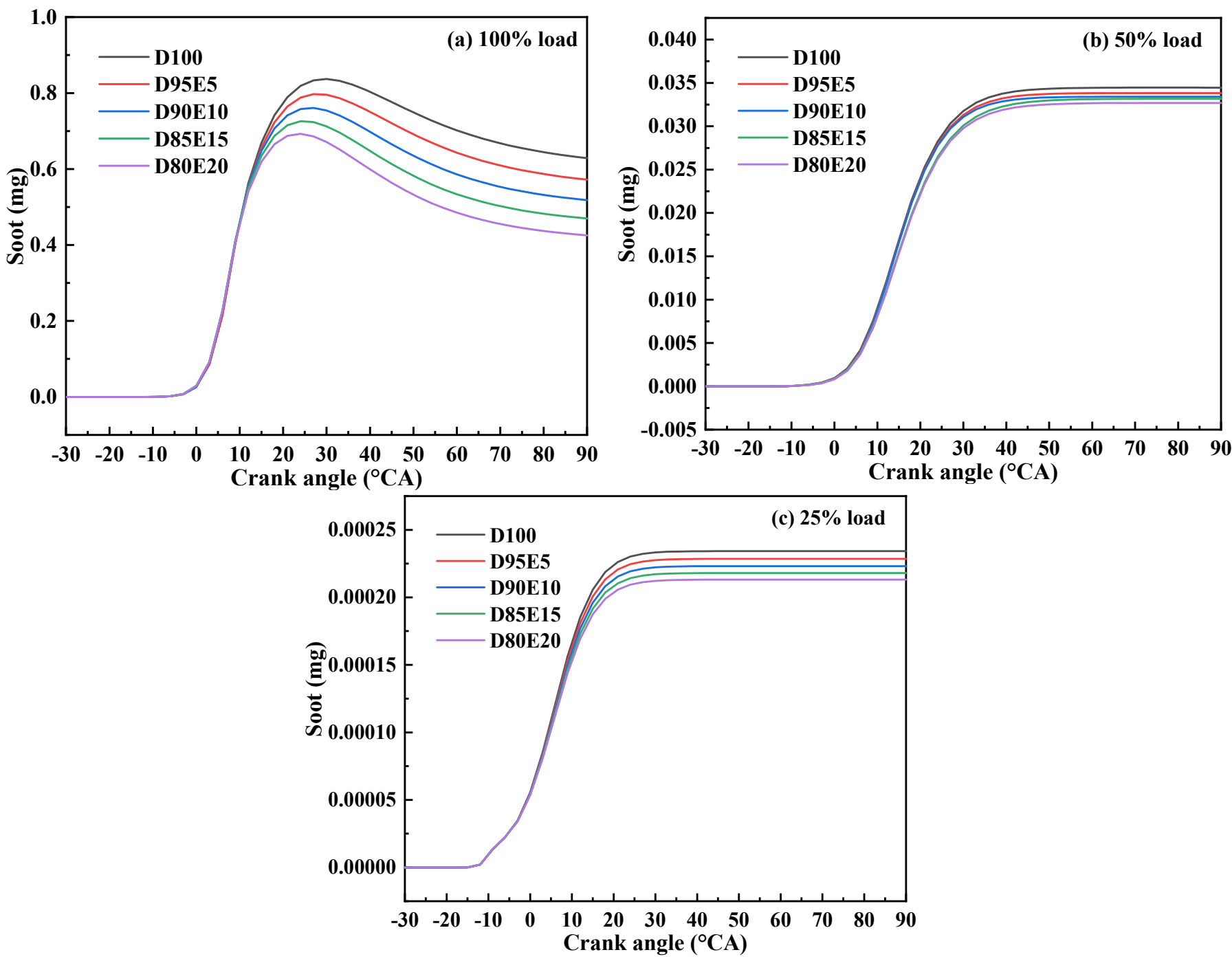

Figure 13. Effects of diesel/ethanol blended fuels with different blending ratios on soot emission under different loading conditions.

\section{Conclusions}

Due to the global energy crisis [51-56] and environmental problems [57-61], the development of diesel engines is also facing great challenges. In this paper, our main conclusions are as follows:

(1) Diesel/ethanol blended fuels improve the brake thermal efficiency of the engine. Since ethanol is an oxygenated fuel, the oxygen content of the blended fuel increases, and the brake thermal efficiency of the engine improves. For example, when the ethanol content in the blended fuel increases to $20 \%$, the cylinder pressure increases by $0.46 \%$. In addition, compared with D100, the engine power of D80E20 reduces by about $4.12 \%$; this is because ethanol has a high oxygen content and low calorific value;

(2) Diesel/ethanol blended fuel increases BSFC and reduces power. The blended fuels of D95E5, D90E10, D85E15, and D80E20 decrease by $0.96 \%, 1.97 \%, 2.99 \%$, and $4.12 \%$, respectively; this is mainly due to the low calorific value of ethanol. However, the BTE of the engine improves due to the increase in oxygen content; 
(3) Diesel/ethanol blended fuel will lead to increase of the soot, the carbon monoxide, and the $\mathrm{NO}_{\mathrm{x}}$ emissions. Compared with D100, the $\mathrm{CO}$ and soot emissions of D80E20 increase by $63.25 \%$ and $17.24 \%$, respectively. As the oxygen content of the blended fuel increases, the combustion is more sufficient, and the soot emission reduces.

In conclusion, adding ethanol to diesel engines can improve combustion and emission characteristics. This trend is worth studying. Further research is needed to obtain more accurate results.

Author Contributions: Conceptualization, Z.W. and L.L.; software, Z.W.; formal analysis, Z.W. and L.L.; investigation, Z.W. and L.L.; resources, L.L.; writing-original draft preparation, Z.W.; writingreview and editing, Z.W. and L.L.; supervision, L.L.; funding acquisition, Z.W. and L.L. All authors have read and agreed to the published version of the manuscript.

Funding: This research was funded by the key research and development project of Hunan Province (2021NK2023) and the Special funds for the construction of the innovative Hunan Province (2019NK2022).

Institutional Review Board Statement: Not applicable.

Informed Consent Statement: Not applicable.

Data Availability Statement: All data used to support the findings of this study are included within the article.

Conflicts of Interest: The authors declare that they have no conflict of interest regarding the publication of this paper.

\section{References}

1. Zhang, Z.; Ye, J.; Tan, D.; Feng, Z.; Luo, J.; Tan, Y.; Huang, Y. The effects of $\mathrm{Fe}_{2} \mathrm{O}_{3}$ based DOC and SCR catalyst on the combustion and emission characteristics of a diesel engine fueled with biodiesel. Fuel 2021, 290, 120039. [CrossRef]

2. Chen, S.; Tian, J.; Li, J.; Li, W.; Zhang, Z. Investigation of the Performance and Emission Characteristics of a Diesel Engine with Different Diesel-Methanol Dual-Fuel Ratios. Processes 2021, 9, 1944. [CrossRef]

3. Cai, T.; Zhao, D.; Wang, B.; Li, J.; Guan, Y. NO emission and thermal performances studies on premixed ammonia-oxygen combustion in a $\mathrm{CO}_{2}$-free micro-planar combustor. Fuel 2021, 280, 118554. [CrossRef]

4. Zhang, Z.; Ye, J.; Lv, J.; Xu, W.; Tan, D.; Jiang, F.; Huang, H. Investigation on the effects of non-uniform porosity catalyst on SCR characteristic based on the field synergy analysis. J. Environ. Chem. Eng. 2022, 10, 107056. [CrossRef]

5. E, J.; Zhang, Z.; Chen, J.; Pham, M.; Zhao, X.; Peng, Q.; Zhang, B.; Yin, Z. Performance and emission evaluation of a marine diesel engine fueled by water biodiesel-diesel emulsion blends with a fuel additive of a cerium oxide nanoparticle. Energy Convers. Manag. 2018, 169, 194-205. [CrossRef]

6. Cai, T.; Zhao, D. Mitigating NOx emissions from an ammonia-fueled micro-power system with a perforated plate implemented. J. Hazard. Mater. 2021, 401, 123848. [CrossRef]

7. E, J.; Zhao, X.; Qiu, L.; Wei, K.; Zhang, Z.; Deng, Y.; Han, D.; Liu, G. Experimental investigation on performance and economy characteristics of a diesel engine with variable nozzle turbocharger and its application in urban bus. Energy Convers. Manag. 2019, 193, 149-161. [CrossRef]

8. Peng, Q.; Xie, B.; Yang, W.; Tang, S.; Li, Z.; Zhou, P.; Luo, N. Effects of porosity and multilayers of porous medium on the hydrogen-fueled combustion and micro-thermophotovoltaic. Renew. Energy 2021, 174, 391-402. [CrossRef]

9. Li, W.; Ji, J.; Huang, L.; Guo, Z. Global dynamics of a controlled discontinuous diffusive SIR epidemic system. Appl. Math. Lett. 2021, 121, 107420. [CrossRef]

10. Fan, L.; Cheng, F.; Zhang, T.; Liu, G.; Yuan, J.; Mao, P. Visible-light photoredox-promoted desilylative allylation of a-silylamines: An efficient route to synthesis of homoallylic amines. Tetrahedron Lett. 2021, 81, 153357. [CrossRef]

11. Wei, L.; Cheung, C.S.; Ning, Z. Effects of biodiesel-ethanol and biodiesel-butanol blends on the combustion, performance and emissions of a diesel. Energy 2018, 155, 957-970. [CrossRef]

12. Lu, Y.; Jiang, Z.; Geng, N.; Jiang, S.; Xie, X. Appointment window scheduling with wait-dependent abandonment for elective inpatient admission. Int. J. Prod. Res. 2021, 1-17. [CrossRef]

13. Wei, L.; Yao, C.; Wang, Q.; Pan, W.; Han, G. Combustion and emission characteristics of a turbocharged diesel engine using high premixed ratio of methanol and diesel fuel. Fuel 2015, 140, 156-163. [CrossRef]

14. Ning, L.; Duan, Q.; Zhanming, C.; Kou, H.; Liu, B.; Yang, B.; Zeng, K. A comparative study on the combustion and emissions of a non-road common rail diesel engine fueled with primary alcohol fuels (methanol, ethanol, and n-butanol)/diesel dual fuel. Fuel 2020, 266, 117034. [CrossRef]

15. Liang, J.; Zhang, Q.; Chen, Z.; Zheng, Z.; Yang, C.; Ma, Q. The combustion and emission characteristics of diesel-ethanol blends with THF as cosolvents in a diesel engine operating with EGR. Fuel 2021, 298, 120843. [CrossRef] 
16. Zhang, Z.; Tian, J.; Li, J.; Ji, H.; Tan, D.; Luo, J.; Jiang, Y.; Yang, D.; Cui, S. Effects of Different Mixture Ratios of Methanol-Diesel on the Performance Enhancement and Emission Reduction for a Diesel Engine. Processes 2021, 9, 1366. [CrossRef]

17. Fan, C.; Wei, J.; Huang, H.; Pan, M.; Fu, Z. Chemical feature of the soot emissions from a diesel engine fueled with methanol-diesel blends. Fuel 2021, 297, 120739. [CrossRef]

18. Feng, C.; Deng, Y.; Chen, L.; Han, W.; E, J.; Wei, K.; Han, D.; Zhang, B. Hydrocarbon emission control of a hydrocarbon adsorber and converter under cold start of the gasoline engine. Energy 2022, 239, 122138. [CrossRef]

19. Shang, Z.; Yu, X.; Shi, W.; Huang, S.; Li, G.; Guo, Z.; He, F. Numerical research on effect of hydrogen blending fractions on idling performance of an n-butanol ignition engine with hydrogen direct injection. Fuel 2019, 258, 116082. [CrossRef]

20. Kim, K.; Choi, B.; Park, S.H.; Kim, E.; Chiaramonti, D. Emission characteristics of compression ignition (CI) engine using diesel blended with hydrated butanol. Fuel 2019, 257, 116037. [CrossRef]

21. Kattela, S.; Vysyaraju, R.; Surapaneni, S.; Ganji, P. Effect of n-butanol/diesel blends and piston bowl geometry on combustion and emission characteristics of CI engine. Environ. Sci. Pollut. Res. 2019, 26, 1661-1674. [CrossRef]

22. Jin, C.; Zhang, X.; Wang, X.; Xiang, Y.; Cui, X.; Yin, Z.; Ji, J.; Liu, H. Effects of polyoxymethylene dimethyl ethers on the solubility of ethanol/diesel and hydrous ethanol/diesel fuel blends. Energy Sci. Eng. 2019, 7, 2855-2865. [CrossRef]

23. Jamrozik, A. The effect of the alcohol content in the fuel mixture on the performance and emissions of a direct injection diesel engine fueled with diesel-methanol and diesel-ethanol blends. Energy Convers. Manag. 2017, 148, 461-476. [CrossRef]

24. Zhang, Z.; E, J.; Chen, J.; Zhao, X.; Zhang, B.; Deng, Y.; Peng, Q.; Yin, Z. Effects of boiling heat transfer on the performance enhancement of a medium speed diesel engine fueled with diesel and rapeseed methyl ester. Appl. Therm. Eng. 2020, 169, 114984. [CrossRef]

25. Imdadul, H.K.; Masjuki, H.H.; Kalam, M.A.; Zulkifli, N.W.M.; Alabdulkarem, A.; Rashed, M.M.; Teoh, Y.H.; How, H.G. Higher alcohol-biodiesel-diesel blends: An approach for improving the performance, emission, and combustion of a light-duty diesel engine. Energy Convers. Manag. 2016, 111, 174-185. [CrossRef]

26. Dong, S. Investigations on the effects of fuel stratification on auto-ignition and combustion process of an ethanol/diesel dual-fuel engine. Appl. Energy 2018, 230, 19-30. [CrossRef]

27. Pedrozo, V.; May, I.; Guan, W.; Zhao, H. High efficiency ethanol-diesel dual-fuel combustion: A comparison against conventional diesel combustion from low to full engine load. Fuel 2018, 230, 440-451. [CrossRef]

28. Zhang, Z.; E, J.; Chen, J.; Zhu, H.; Zhao, X.; Han, D.; Zuo, W.; Peng, Q.; Gong, J.; Yin, Z. Effects of low-level water addition on spray, combustion and emission characteristics of a medium speed diesel engine fueled with biodiesel fuel. Fuel 2019, 239, 245-262. [CrossRef]

29. Zang, R.; Yao, C. Numerical Study of Combustion and Emission Characteristics of a Diesel/Methanol Dual Fuel (DMDF) Engine. Energy Fuels 2015, 29, 150529125137009. [CrossRef]

30. Fan, B.; Pan, J.; Liu, Y.; Chen, W.; Lu, Y.; Otchere, P. Numerical investigation of mixture formation and combustion in a hydrogen direct injection plus natural gas port injection (HDI + NGPI) rotary engine. Int. J. Hydrogen Energy 2018, 43, 4632-4644. [CrossRef]

31. Zhang, Z.; Tian, J.; Xie, G.; Li, J.; Xu, W.; Jiang, F.; Huang, Y.; Tan, D. Investigation on the combustion and emission characteristics of diesel engine fueled with diesel/methanol/n-butanol blends. Fuel 2022, 314, 123088. [CrossRef]

32. Gong, C.; Liu, J.; Peng, L.; Liu, F. Numerical study of effect of injection and ignition timings on combustion and unregulated emissions of DISI methanol engine during cold start. Renew. Energy 2017, 112, 457-465. [CrossRef]

33. Poorghasemi, K.; Saray, R.; Ansari, E.; Irdmousa, B.; Shahbakhti, M.; Naber, J. Effect of diesel injection strategies on natural gas/diesel RCCI combustion characteristics in a light duty diesel engine. Appl. Energy 2017, 199, 430-446. [CrossRef]

34. Tan, D.; Chen, Z.; Li, J.; Luo, J.; Yang, D.; Cui, S.; Zhang, Z. Effects of Swirl and Boiling Heat Transfer on the Performance Enhancement and Emission Reduction for a Medium Diesel Engine Fueled with Biodiesel. Processes 2021, 9, 568. [CrossRef]

35. Zhang, Z.; Li, J.; Tian, J.; Xie, G.; Tan, D.; Qin, B.; Huang, Y.; Cui, S. Effects of Different Diesel-Ethanol Dual Fuel Ratio on Performance and Emission Characteristics of Diesel Engine. Processes 2021, 9, 1135. [CrossRef]

36. Wang, C.H.; Zhao, D.; Schluter, J.; Holzäpfel, F.; Stephan, A. LES study on the shape effect of ground obstacles on wake vortex dissipation. Aerosp. Sci. Technol. 2017, 63, 245-258. [CrossRef]

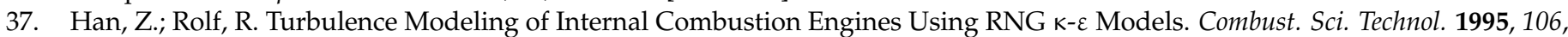
267-295. [CrossRef]

38. Yakhot, V.; Orszag, S.A.; Thangam, S.; Gatski, T.; Speziale, C. Development of Turbulence Models for Shear Flows by a Double Expansion technique. Phys. Fluids A 1992, 4, 1510-1520. [CrossRef]

39. Zhang, Z.; E, J.; Deng, Y.; Pham, M.; Zuo, W.; Peng, Q.; Yin, Z. Effects of fatty acid methyl esters proportion on combustion and emission characteristics of a biodiesel fueled marine diesel engine. Energy Convers. Manag. 2018, 159, 244-253. [CrossRef]

40. Gonzalez, D.M.; Lian, Z.; Reitz, R. Modeling Diesel Engine Spray Vaporization and Combustion. SAE Trans. 1992, 101, $1064-1076$.

41. Senecal, P.; Pomraning, E.; Richards, K.; Briggs, T.; Choi, C.; McDavid, R.; Patterson, M. Multi-Dimensional Modeling of DirectInjection Diesel Spray Liquid Length and Flame Lift-off Length using CFD and Parallel Detailed Chemistry. SAE Tech. Pap. 2003, 112, 1043. [CrossRef]

42. Turns, S.R. An Introduction to Combustion; McGraw-Hill, Inc.: New York, NY, USA, 1996.

43. Heywood, J. Internal Combustion Engine Fundamentals; McGraw-Hill: New York, NY, USA, 1988.

44. Hiroyasu, H.; Kadota, T. Models for Combustion and Formation of Nitric Oxide and Soot in Direct Injection Diesel Engines; SAE International: Warrendale, PA, USA, 1976. [CrossRef] 
45. Nayak, S.; Mishra, P.; Noor, M.M. Simultaneous reduction of nitric oxide and smoke opacity in TDI dual fuel engine fuelled with calophyllum-diesel blends and waste wood chip gas for modified inlet valve and injector nozzle geometry. Energy 2019, 189, 116238. [CrossRef]

46. Liu, J.; Wang, F.; Li, S. The effects of EGR and injection timing on the engine combustion and PM emission performances fueled with diesel-ethanol blends. Therm. Sci. 2018, 22, 1457-1467. [CrossRef]

47. E, J.; Liu, G.; Zhang, Z.; Han, D.; Chen, J.; Wei, K.; Gong, J.; Yin, Z. Effect analysis on cold starting performance enhancement of a diesel engine fueled with biodiesel fuel based on an improved thermodynamic model. Appl. Energy 2019, 243, 321-335. [CrossRef]

48. Han, J.; Somers, L.M.T.; Cracknell, R.; Joedicke, A.; Wardle, R.; Mohan, V.R.R. Experimental investigation of ethanol/diesel dual-fuel combustion in a heavy-duty diesel engine. Fuel 2020, 275, 117867. [CrossRef]

49. Sayin, C. Engine performance and exhaust gas emissions of methanol and ethanol-diesel blends. Fuel 2010, 89, 3410-3415. [CrossRef]

50. Alptekin, E. Evaluation of ethanol and isopropanol as additives with diesel fuel in a CRDI diesel engine. Fuel 2017, 205, 161-172. [CrossRef]

51. Zuo, H.; Tan, J.; Wei, K.; Huang, Z.; Zhong, D.; Xie, F. Effects of different poses and wind speeds on wind-induced vibration characteristics of a dish solar concentrator system. Renew. Energy 2021, 168, 1308-1326. [CrossRef]

52. Zuo, H.; Liu, G.; E, J.; Zuo, W.; Wei, K.; Hu, W.; Tan, J.; Zhong, D. Catastrophic analysis on the stability of a large dish solar thermal power generation system with wind-induced vibration. Sol. Energy 2019, 183, 40-49. [CrossRef]

53. Zuo, H.; Zhang, B.; Huang, Z.; Wei, K.; Tan, J. Effect analysis on SOC values of the power lithium manganate battery during discharging process and its intelligent estimation. Energy 2022, 238, 121854. [CrossRef]

54. Ma, Y.; Liu, C.; E, J.; Mao, X.; Yu, Z. Research on modeling and parameter sensitivity of flow and heat transfer process in typical rectangular microchannels: From a data-driven perspective. Int. J. Thermal Sci. 2022, 172, 107356. [CrossRef]

55. E, J.; Cai, L.; Li, J.; Ding, J.; Chen, J.; Luo, B. Effects analysis on the catalytic combustion and heat transfer performance enhancement of a non-premixed hydrogen/air micro combustor. Fuel 2022, 309, 122125. [CrossRef]

56. Zhang, B.; Zuo, H.; Huang, Z.; Tan, J.; Zuo, Q. Endpoint forecast of different diesel-biodiesel soot filtration process in diesel particulate filters considering ash deposition. Fuel 2020, 272, 117678. [CrossRef]

57. E, J.; Zhao, M.; Zuo, Q.; Zhang, B.; Zhang, Z.; Peng, Q.; Han, D.; Zhao, X.; Deng, Y. Effects analysis on diesel soot continuous regeneration performance of a rotary microwave-assisted regeneration diesel particulate filter. Fuel 2020, 260, 116353. [CrossRef]

58. Chen, L.; Deng, Y.; Feng, C.; Han, W.; E, J.; Wang, C.; Han, D.; Zhang, B. Effects of zeolite molecular sieve on the hydrocarbon adsorbent performance of gasoline engine of during cold start. Fuel 2022, 310, 122427. [CrossRef]

59. E, J.; Luo, J.; Han, D.; Tan, Y.; Feng, C.; Deng, Y. Effects of different catalysts on light-off temperature of volatile organic components in the rotary diesel particulate filter during the regeneration. Fuel 2022, 310, 122451. [CrossRef]

60. Chen, J.; Meng, T.; Leng, E.; E, J. Review on metal dissolution characteristics and harmful metals recovery from electronic wastes by supercritical water. J. Hazard. Mater. 2022, 424, 127693. [CrossRef]

61. Chen, J.; Wang, Q.; Wei, H.; Meng, T.; E, J.; Leng, E.; Zhang, F.; Liao, G. Molecular dynamic study on mechanisms of polyvinylidene fluoride decomposition by using supercritical water. Chem. Eng. J. 2022, 431, 133958. [CrossRef] 